American Journal of Pharmaceutical Education 2016; 80 (7) Article 116.

\title{
RESEARCH
}

\section{Variables Affecting Pharmacy Students' Patient Care Interventions during Advanced Pharmacy Practice Experiences}

\author{
Laura L. Bio, PharmD, Brandon J. Patterson, PharmD, PhD, Sanchita Sen, PharmD, \\ Angela L. Bingham, PharmD, Jane F. Bowen, PharmD, Benjamin Ereshefsky, PharmD, Laura A. \\ Siemianowski, PharmD \\ University of the Sciences Philadelphia College of Pharmacy, Philadelphia, Pennsylvania \\ Submitted July 2, 2015; accepted September 9, 2015; published September 25, 2016.
}

Objective. To identify the temporal effect and factors associated with student pharmacist self-initiation of interventions during acute patient care advanced pharmacy practice experiences (APPE).

Methods. During the APPE, student pharmacists at an academic medical center recorded their therapeutic interventions and who initiated the intervention throughout clinical rotations. At the end of the APPE student pharmacists completed a demographic survey.

Results. Sixty-two student pharmacists were included. Factors associated with lower rates of self-initiated interventions were infectious diseases and pediatrics APPEs and an intention to pursue a postgraduate residency. Timing of the APPE, previous specialty elective course completion, and previous hospital experience did not result in any significant difference in self-initiated recommendations.

Conclusion. Preceptors should not base practice experience expectations for self-initiated interventions on previous student experience or future intentions. Additionally, factors leading to lower rates of self-initiated interventions on infectious diseases or pediatrics APPEs should be explored.

Keywords: advanced pharmacy practice experiences (APPE), intervention, patient care, rotation

\section{INTRODUCTION}

The degree shift from a baccalaureate to doctor of pharmacy (PharmD) with subsequent revisions in experiential education has altered the educational landscape of pharmacy. The Accreditation Council for Pharmacy Education (ACPE) Standards on Experiential Education mandate opportunities for students to perform patientcentered care activities in a variety of settings (eg, community pharmacy/ambulatory care, hospital/health system). ${ }^{1}$ Other professional health care programs, such as medicine and nursing, include direct and indirect patient-care activities across the curriculum to ensure students achieve practicefocused core competencies by graduation. ${ }^{2,3}$ A goal of experiential education for students across disciplines is to develop skills necessary to practice independently upon graduation and to collaborate interprofessionally to deliver team-based patient care in diverse practice settings.

The profession of pharmacy has shifted from productoriented to service-oriented, and practice-ready pharmacists are required to have the ability to self-initiate

Corresponding author: Laura LoCastro Bio, Department of Pharmacy Practice and Pharmacy Administration, Philadelphia College of Pharmacy, University of the Sciences, 600 South 43rd St., Philadelphia, PA 19104. Tel: 215-596-8703. Fax: 215-596-8586. E-mail: Laura.locastro.bio@gmail.com recommendations or interventions to improve patient care. ${ }^{4,5}$ Provision of comprehensive medication management to optimize patient outcomes in collaboration with members of an interdisciplinary team in all health care settings is expected of clinical pharmacists. The literature on developing student pharmacists' abilities to assess patients for medication-related problems and to self-initiate interventions is sparse. Therefore, scholarship of teaching and learning on student pharmacists' self-initiation of interventions is necessary to advance pharmacy pedagogical content knowledge.

Interventions by clinical pharmacists have HADa positive impact on patient care within an institution, ${ }^{6-9}$ as have interventions by advanced pharmacy practice experience (APPE) student pharmacists. ${ }^{10}$ Preceptor expectations of APPE students' knowledge, performance, and ability to make evidence-based therapeutic interventions during the practice experience year may increase over time, based on preconceived notions that prior experiences will positively impact their skills. During an acute care practice experience, medication-related problems and interventions may be initiated by the student's preceptor, the student, or another member of the interdisciplinary health care team. Typically, preceptors mentor and direct students to identify medication-related problems and appropriate interventions with the expectation that students will develop the skill to 


\section{American Journal of Pharmaceutical Education 2016; 80 (7) Article 116.}

independently identify potential interventions during the practice experience. Preceptors might expect students to self-initiate interventions more frequently by the end of a practice experience or towards the second half of the practice experience year.

The purpose of this study was to identify differences in student pharmacists' self-initiation of interventions across the temporal sequence of APPEs and across medical services within an academically affiliated health system. Additionally, an initial exploration of factors believed to be associated with student pharmacists' self-initiation of interventions (eg, completion of a specialty clinical elective within the pharmacy curriculum, previous pharmacy work experience, and future aspirations) was conducted.

\section{METHODS}

This study was a longitudinal, prospective cohort analysis of student pharmacists' interventions over three academic years (2011-2014). Student pharmacists in the final professional year of the PharmD curriculum at the Philadelphia College of Pharmacy (PCP) complete seven 5-week practice experiences, during some of which student pharmacists provide direct patient care under the supervision of practicing pharmacists. Approximately 200 PCP student pharmacists complete APPE experiences each year in various practice settings where more than 60 full-time faculty and 800 adjunct faculty members provide direct mentorship and supervision of students' activities.

The study took place at a single practice experience site with full-time faculty members practicing in critical care, infectious diseases, internal medicine, and pediatrics. These four acute patient care (APC) practice experiences were offered at different times over the academic years by various faculty preceptors. During their APC APPEs, students attended daily interdisciplinary medical rounds while learning how to comprehensively review patient medication profiles, identify drug-therapy problems, and search for and interpret appropriate medical literature to propose and implement evidence-based pharmacotherapeutic recommendations. As part of the practice experience structure, students and/or preceptors identified and discussed drug-therapy problems and therapeutic interventions. After discussion with the preceptor, students provided recommendations to the health care team. Only interventions made by students that impacted patient care were documented on their log with details of the interaction, which is required for the APC practice experience at this site.

During students' APC practice experience orientation, the principal investigator provided a paper intervention log containing detailed instructions on how to document all interventions during the practice experience (Table 3). Students recorded the service they were on (ie, internal medicine, pediatrics, critical care, infectious disease) and the practice experience temporal sequence (eg, first rotation, second rotation). For each intervention, students documented the week (eg, first week, second week) of the rotation in which the intervention occurred, who initiated the intervention (eg, self, pharmacist preceptor, physician, nurse), the type of intervention (eg, initiation of medication regimen, including nonpharmacologic intervention), modification of medication regimen, discontinuation of medication regimen, drug information (consult vs offered, monitoring), the primary medication involved in the intervention, the recommendation made to the health care team, and whether the intervention was accepted. For example, if a student brought the intervention to the attention of the preceptor to discuss prior to making the intervention, the intervention was documented as "self-initiated." If the preceptor brought the intervention to the attention of the student and the student made the recommendation/intervention, not the preceptor, then the intervention was documented as "preceptor-initiated." The students were instructed not to document preceptor-performed interventions. Any other health care provider or patient who asked a question or consult of the student could be deemed an initiator if the student performed an intervention. This type of intervention was documented with the specific initiator, (ie, resident/physician, pharmacist, patient/caregiver, medical student, nurse).

At the end of the practice experience, students were approached by their preceptor investigator to obtain informed consent for inclusion in the study. Upon consenting, students completed a demographic survey to capture data on their previous pharmacy work experience, whether they completed a specialty patient-care elective within the PCP curriculum, number and type of APPEs completed previously, and future career aspirations, such as desire to pursue postgraduate training (ie, pharmacy residency, clinical fellowship, industry fellowship), community pharmacy practice, hospital pharmacy practice, industry, or other. Students were excluded from the study if consent was not obtained, the intervention log was incomplete, or if the APPE was incomplete for any reason. All study procedures were approved by Cooper University Hospital (CUH) and University of the Sciences institutional review boards.

Descriptive statistics, including mean, standard deviation (SD), frequency, and percentage were analyzed. All data analyses were conducted using SAS software, v.9.4 (SAS, Cary, NC). An a priori level of $\alpha=0.05$ was used for determining statistical significance. The primary outcome of the study was percentage of interventions 


\section{American Journal of Pharmaceutical Education 2016; 80 (7) Article 116.}

self-initiated by the student pharmacist regardless of type of intervention. Proportion of self-initiated interventions per APPE was defined as: number of self-initiations as the numerator and total interventions performed by the student as the denominator. A generalized linear model was created with the dependent variable as the proportion of interventions self-initiated for each studentAPPE combination. The unit of analysis was the student on each APPE. The regression model included variables accounting for completion of a clinical elective course relevant to the practice setting (eg, completion of the pediatric pharmacy elective course within the curriculum and APC APPE in pediatrics), previous hospital work experience, medical service assigned, intention to complete a residency on graduation, and temporal sequence of the practice experience. The model was also adjusted for overdispersion. Residual plots were constructed to examine violation of statistical assumptions. Overall model fit and beta estimates for each factor were calculated.

\section{RESULTS}

Of the 104 pharmacy students who completed an APC APPE with a PCP faculty member during the 2011 to 2014 academic years, 62 students consented and completed all necessary documentation (Table 1). Forty-two students were excluded because of incomplete documentation (intervention log or demographic survey omitted data). Approximately half of the student pharmacists in each academic year participated in the APC APPE in the early part of the year (ie, during the first through third rotation). Approximately one-third of student pharmacists had previous hospital work experience (30.6\%). Forty-two percent had completed a clinical elective course relating to their APC APPE. Half of student pharmacists expressed interest in postgraduate training of some form. A majority of student pharmacists' interventions were self-initiated [mean $62.7 \%(23.6 \% \mathrm{SD})]$. Most interventions were accepted by the medical staff [mean $82.3 \%(14.5 \% \mathrm{SD})$ ].

Relative to students on an internal medicine rotation, students on pediatrics or infectious diseases rotations were less likely to self-initiate interventions $(-1.14, p<0.01$, Figure 1/Table 2). Significant differences in proportion of self-initiated interventions were identified among students participating in specialty (ie, pediatrics/infectious disease) rotations compared to students on general rotations (ie, internal medicine). This difference was not significant for students on medical intensive care compared with students on internal

Table 1. Pharmacy Student Demographics by Academic Year

\begin{tabular}{|c|c|c|c|c|}
\hline & All students $N=62$ & 2011-2012 N=25 & 2012-2013 N=19 & 2013-2014 N=18 \\
\hline \multicolumn{5}{|l|}{ Rotation Temporality (\%) } \\
\hline APPE 1-3 & $32(51.6)$ & $11(44)$ & $11(57.9)$ & $10(55.6)$ \\
\hline APPE 4-6 & $13(21.0)$ & $5(20)$ & $6(31.6)$ & $2(11.1)$ \\
\hline APPE 7-9 & $17(27.4)$ & $9(36)$ & $2(10.5)$ & $6(33.3)$ \\
\hline \multicolumn{5}{|l|}{ Rotation Service $(\%)^{*}$} \\
\hline MICU & $25(40.3)$ & $11(44)$ & $13(68.4)$ & $1(5.6)$ \\
\hline ID & $6(9.7)$ & $2(8)$ & 0 & $4(22.2)$ \\
\hline IM & $17(27.4)$ & $6(24)$ & $2(10.5)$ & $9(50)$ \\
\hline Peds & $14(22.6)$ & $6(24)$ & $4(21.1)$ & $4(22.2)$ \\
\hline \multicolumn{5}{|l|}{ Pharmacy Work Experience (\%) } \\
\hline Community & $34(54.8)$ & $15(60)$ & $9(47.4)$ & $10(55.5)$ \\
\hline Hospital & $19(30.6)$ & $7(28)$ & $6(31.6)$ & $6(33.3)$ \\
\hline None & $5(8.1)$ & $1(4)$ & $3(15.8)$ & $1(5.6)$ \\
\hline Other & $4(6.5)$ & $2(8)$ & $1(5.2)$ & $1(5.6)$ \\
\hline $\begin{array}{l}\text { Completion of Professional Therapeutic } \\
\text { Elective Course Specific to the APPE (\%) }\end{array}$ & $26(42)$ & $14(56)$ & $7(36.8)$ & $5(27.7)$ \\
\hline \multicolumn{5}{|l|}{ Future Aspirations (\%) } \\
\hline Postgraduate training & $32(51.6)$ & $10(40)$ & $11(58)$ & $11(61.1)$ \\
\hline Community pharmacy & $17(27.5)$ & $7(28)$ & $5(26.3)$ & $5(27.7)$ \\
\hline Hospital pharmacy & $7(11.3)$ & $5(20)$ & $1(5.2)$ & $1(5.6)$ \\
\hline Undecided & $3(4.8)$ & $3(12)$ & 0 & 0 \\
\hline Other & $3(4.8)$ & 0 & $2(10.5)$ & $1(5.6)$ \\
\hline
\end{tabular}

$\mathrm{MICU}=$ medical intensive care unit; $\mathrm{ID}=$ infectious diseases; $\mathrm{IM}=$ internal medicine; Peds=general pediatric unit ${ }^{*} p=0.003$ (Chi-square) 


\section{American Journal of Pharmaceutical Education 2016; 80 (7) Article 116.}

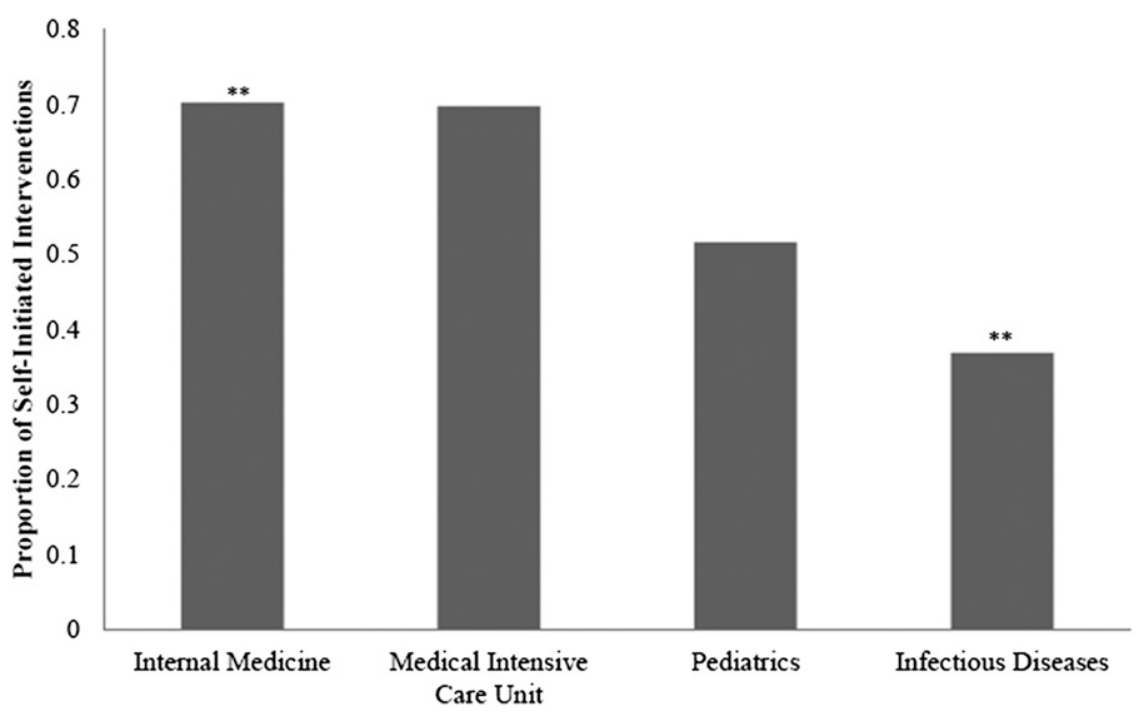

Figure 1. Comparison of Proportion of Self-Initiation Interventions across Medical Services. Significant differences in proportion of self-initiated interventions for students on infectious diseases APPE compared to students on internal medicine APPE, but not for students on medical intensive care unit or pediatric APPE compared to students on internal medicine APPE. ${ }^{* *} p<0.01$.

medicine rotations. Additionally, students who aspired to postgraduation residency were less likely to self-initiate interventions compared to those without postgraduate intentions $(-0.79, p<0.05$, Table 2). However, no significant differences were found across practice experience

Table 2. Report of Generalized Linear Regression Model for Self-initiated Interventions ${ }^{\mathrm{a}}$

\begin{tabular}{|c|c|c|c|}
\hline Variable & Estimate & Std. Error & $\begin{array}{c}\text { Wald } \\
\text { Chi-Square }\end{array}$ \\
\hline Intercept & $-1.24^{\mathrm{b}}$ & 0.32 & 15.54 \\
\hline Elective $^{c}$ & -0.28 & 0.28 & 0.97 \\
\hline $\begin{array}{l}\text { Hospital } \\
\text { Experience }^{\mathrm{d}}\end{array}$ & $-0.67^{b}$ & 0.28 & 5.53 \\
\hline $\begin{array}{l}\text { Pediatrics Medical } \\
\text { Service }^{\mathrm{e}}\end{array}$ & -0.36 & 0.41 & 0.76 \\
\hline $\begin{array}{l}\text { Infectious Diseases } \\
\text { Medical Service }\end{array}$ & $-1.85^{b}$ & 0.52 & 13.12 \\
\hline $\begin{array}{l}\text { Medical Intensive Care } \\
\text { Unit Medical Service }\end{array}$ & -0.21 & 0.33 & 0.52 \\
\hline $\begin{array}{l}\text { Postgraduate Residency } \\
\text { Plans }{ }^{f}\end{array}$ & $-0.66^{b}$ & 0.27 & 5.92 \\
\hline Rotations $1-3^{\mathrm{g}}$ & -0.32 & 0.33 & 0.91 \\
\hline Rotations $4-6^{\mathrm{g}}$ & -0.74 & 0.43 & 2.97 \\
\hline
\end{tabular}

${ }^{a} \mathrm{n}=62$; Model fit statistics: $\mathrm{A} 1 \mathrm{C}=556.12$, Deviance $/ \mathrm{DF}=6.40$, Scaled deviance $=1.13$; Binary outcome events $=1397$, and nonevents $=657$

${ }^{\mathrm{b}} p<0.01$

${ }^{\mathrm{c}}$ Reference group is no elective

${ }^{\mathrm{d}}$ Reference group is no hospital experience

${ }^{\mathrm{e}}$ Reference group is internal medicine service

${ }^{\mathrm{f}}$ Reference group is no postgraduate residency plans

${ }^{\mathrm{g}}$ Reference group is APPEs 7-9 temporality (Figure 2). Full results of the generalized regression model are shown in Table 2.

\section{DISCUSSION}

We sought to evaluate the effect of rotation, curricular experience, and future aspirations on student initiated interventions during an APC APPE with a PCP faculty member at a single practice site. We identified no relationship between practice experience temporality or completion of a specialty elective course related to the APPE medical service with self-initiation of clinical interventions. However, the rotation service and previous hospital experience did matter. These findings may impact future APPE preceptors' structure for student development in many ways. For example, as student pharmacists progress through the APPE year, preceptors may unknowingly increase expectations based on the presumed student experience. Based on these findings, it would be inappropriate to expect a student on practice experience later in the academic year to originate patient care interventions at a greater rate than a student earlier in the year since practice experience temporality was not found to impact self-initiated interventions. Additionally, the inclusion of introductory pharmacy practice experiences (IPPEs), specifically in hospital or health-system settings, appears to be a useful exercise, maybe increasing students' self-efficacy and increasing knowledge and skills learned during these initial formative experiences. Future research could explore the relationship between IPPEs and learning outcomes within and beyond student pharmacists' years in pharmacy school. 


\section{American Journal of Pharmaceutical Education 2016; 80 (7) Article 116.}

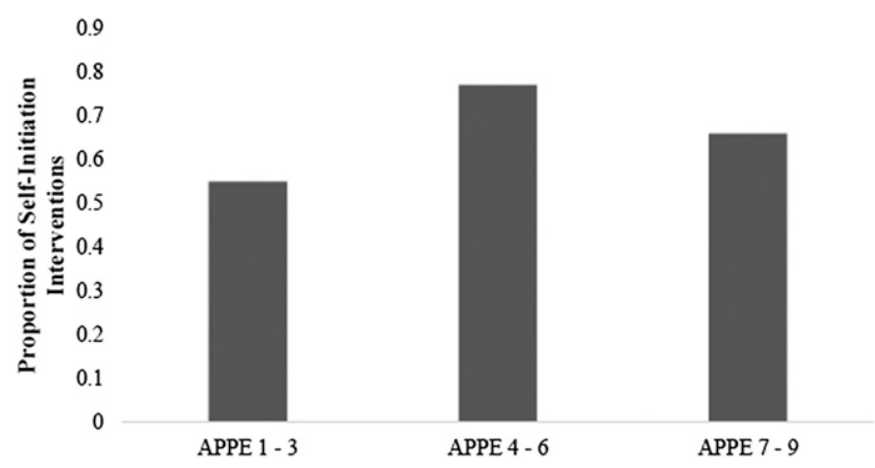

Figure 2. Comparison of Proportion of Self-Initiation Interventions across APPE Temporal Sequence. No significant differences in proportion of self-initiated interventions across APPEs as generalized linear model regression.

Each APC APPE varies in student experiences based on the practice setting, patient acuity, and preceptors' expectations. Therefore, despite having APPEs later in the academic year, some students may not have previously had exposure to clinical rounding services on which to practice and master the skills necessary for patient care interventions. These factors may contribute to the lack of a temporal difference in self-initiated interventions. Alternatively, with nearly $63 \%$ of interventions originating from the student, this does represent a majority of interventions. Future discussions should center on what percentage of interventions made by students should be self-initiated compared to those brought to the student's attention by another health care professional. Once a threshold is determined, studentinitiated interventions could be used as an objective marker of competency and student success on APPEs.

The APPEs medical service may have impacted students' self-initiation of interventions. We found an association that suggests students were more likely to self-initiate interventions in internal medicine settings, rather than infectious disease settings. We hypothesize this difference may be attributable to factors external to the student, such as patient acuity, medical staff acceptance of or familiarity with students, medical staff familiarity with pharmacotherapy specific to the patient population, patient census load, curriculum coverage of medications common to the medical service, and clinical pharmacy faculty time-on-task with regard to student training. These additional factors may diminish or enhance students' abilities to self-initiate interventions across services and were not assessed in the study. Furthermore, internal factors such as students' infectious disease knowledge and self-efficacy to influence change in infectious disease settings may have been diminished for student pharmacists in this study. Future studies should address the influence of potential external confounders on student abilities to initiate interventions on practice experiences.

While the residency finding was unexpected, we urge caution in its interpretation. Although student pharmacists may strive for residency training postgraduation, they may not fully understand the expectations and demands of a residency. An overview of postgraduate training opportunities for pharmacists is presented in the curriculum, but a brief description within a didactic class may not fully convey the rigors of residency training. Our data reflects students' self-reported intention or desire to complete a residency postgraduation but does not reflect achievement of residency program enrollment or completion. A future investigation of student intention during pharmacy education and accomplishment of postgraduate training could help strengthen the understanding of such an intentional measure. Alternatively, students interested in pursuing residencies may seek clinical opportunities they know exceed their current clinical capabilities as a means to

Table 3. Sample of a Student Intervention Log

\begin{tabular}{|c|c|c|c|c|c|}
\hline \multicolumn{3}{|c|}{ Student name: } & \multicolumn{2}{|l|}{ Service: } & \multirow{2}{*}{$\begin{array}{l}\text { Rotation \#: } \\
\text { Accepted? (Y/N) }\end{array}$} \\
\hline Rotation Week \# & Initiator $^{\mathbf{a}}$ & Type of Intervention ${ }^{\mathbf{b}}$ & Primary Medication & Recommendation & \\
\hline & & & & & \\
\hline & & & & & \\
\hline & & & & & \\
\hline & & & & & \\
\hline & & & & & \\
\hline
\end{tabular}

${ }^{\mathrm{a}}$ Initiator (select one primary only): 1= self (student bought the intervention to the attention of the preceptor to discuss final recommendation prior to the student making the intervention); $2=$ preceptor (preceptor brought the intervention to the attention of the student and the student made the recommendation/intervention, not the preceptor-DO NOT document preceptor-made interventions); $3=\mathrm{resident} / \mathrm{physician} ; 4=\mathrm{RPh} ; 5=\mathrm{patient} /$ caregiver; $6=$ med student; $7=$ nurse; $8=$ other

${ }^{\mathrm{b}}$ Type of intervention (select single, most applicable type): $\mathrm{A}=$ initiation of medication regimen; $\mathrm{B}=$ modification of mediation regimen; $\mathrm{C}=$ discontinuation of medication regimen; $\mathrm{D}=$ drug information (consult vs offered); $\mathrm{E}=$ monitoring; $\mathrm{F}=\mathrm{ADR} ; \mathrm{G}=\mathrm{allergy} ; \mathrm{H}=\mathrm{ID}$ approval;

$\mathrm{I}=$ medication reconciliation; $\mathrm{J}=$ patient counseling; $\mathrm{K}=$ other

Cells in log intentionally left blank. 


\section{American Journal of Pharmaceutical Education 2016; 80 (7) Article 116.}

stringently prepare themselves for the next level. In such scenarios, self-initiation of interventions by students would seem less likely. Because of variable practice opportunities and potential student misunderstanding of residency training, preceptors should not change student performance expectations.

Limitations of our study include a small sample size, student self-reporting, and inclusion of students at a single practice experience site. A number of students were excluded from the study because of incomplete intervention logs. This may be a result of students' misunderstanding the importance of documentation and unclear practice experience expectations. We assumed students understood the log's instructions for completion, and typically content was not verified or reviewed by the preceptor prior to collection at the end of the practice experience. There were variations on how students completed the form; some filled it out on a daily basis, while others filled it out retrospectively based on what they noted in their patient packets from days before.

\section{CONCLUSION}

Preceptors of APC APPEs should not have different expectations for students self-initiating interventions based on practice experience temporality, specialty elective course completion, or hospital experience. More APPE students self-initiated interventions on internal medicine compared with specialty services, and fewer interventions were reported among students wishing to pursue postgraduate residency training. These results should be interpreted cautiously, and future studies should include evaluating differences in preceptor activities and expectations on general and specialty services, as well as what correlation, if any, exists between student aspirations and the practice experiences they choose or achievement of postgraduate training.

\section{ACKNOWLEDGMENTS}

Jomy George, PharmD, Craig Whitman, PharmD, Quinn Czosnowski, PharmD, and Trent Towne, PharmD, are acknowledged for their contributions in designing the study methods and as investigators during the first academic study year. We would also like to acknowledge Laura Pontiggia, $\mathrm{PhD}$, for development of statistical analysis strategy.

\section{REFERENCES}

1. Accreditation Council for Pharmacy Education. Accreditation standards and key elements for the professional program in pharmacy leading to the doctor of pharmacy degree. Standards 2016. https:// www.acpe-accredit.org/pdf/Standards2016FINAL.pdf. Accessed June 17, 2015.

2. Association of American Medical Colleges. The AAMC project on the clinical education of medical students. https://www.aamc.org/ download/68522/data/clinicalskillsnutter.pdf. Accessed September 14,2014

3. American Association of Colleges of Nursing. Expectations for practice experiences in the RN to Baccalaureate curriculum: white paper. http://www.aacn.nche.edu/aacn-publications/ white-papers/RN-BSN-White-Paper.pdf. Accessed September 14, 2014.

4. American College of Clinical Pharmacy. Standards of practice for clinical pharmacists. Pharmacotherapy 2014;34(8):794-797.

5. Gubbins PO, Micek ST, Badowski M, et al. Innovation in clinical pharmacy practice and opportunities for academic-practice partnership. Pharmacotherapy. 2014;34(5):e45-e54.

6. Hatoum HT, Hutchinson RA, Witte KW, Newby GP. Evaluation of the contribution of clinical pharmacists: inpatient care and cost reduction. Drug Intel Clin Pharm. 1988;22(3):252-259.

7. Kopp BJ, Mrsan M, Erstad BL, Duby JJ. Cost implications of and potential adverse events prevented by interventions of a critical care pharmacist. Am J Health Syst Pharm. 2007;64 (23):2483-2487.

8. Kucukarslan SN, Peters M, Mlynarek M, Nafziger DA. Pharmacists on rounding teams reduce preventable adverse drug events in hospital general medicine units. Arch Intern Med. 2003;163 (17):2014-2018.

9. McMullin ST, Hennenfent JA, Ritchie DJ, et al. A prospective, randomized trial to assess the cost impact of pharmacist-initiated interventions. Arch Intern Med. 1999;159(19):2306-2309.

10. DiVall MV, Zikaras B, Copeland D, Gonyeau M. School-wide clinical intervention system to document pharmacy students' impact on patient care. Am J Pharm Educ. 2010;74(1):Article 14. 